\title{
INTEGRAÇÃO ENTRE ENSINO, PESQUISA E EXTENSÃO: RELATO DA PRÁTICA NO ESTÁGIO DE DOCÊNCIA
}

\author{
J. L. DE PAULA*, A. L. S. HENRIQUE e M. A. P. REBOUÇAS \\ Instituto Federal de Educação, Ciência e Tecnologia do Rio Grande do Norte \\ jolipa7@hotmail.com*
}

Artigo submetido em outubro/2015 e aceito em dezembro/2015

DOI: $10.15628 /$ rbept.2015.3500

\section{RESUMO}

O presente trabalho se configura como relato da prática desenvolvida ao longo do Estágio de Docência que integrou os eixos ensino, pesquisa e extensão, atrelados à nossa pesquisa de mestrado no PPGEP, que objetiva contribuir para a formação humana integral dos discentes do Curso Superior de Tecnologia em Gestão Ambiental a partir da leitura crítica e da produção de animações de curta duração como instrumentos de educação ambiental. Para tanto, iniciamos a pesquisa junto à turma no semestre 2014.1 e no semestre seguinte
2014.2 demos continuidade, realizando as intervenções e a extensão. Embasamo-nos teoricamente em autores como Antunes (2001), Barbosa Júnior (2011), Benachio (2011), Lorenzi e Pádua (2012), Pimenta e Lima (2012), Purves (2011), Rojo (2012) e Silverstone (2005). Ao final, percebemos que em meio às dificuldades enfrentadas, o estágio nos oportunizou amadurecimento da prática pedagógica integradora e, principalmente, permitiu semear reflexões junto aos gestores ambientais em formação.

PALAVRAS-CHAVE: Estágio de Docência, Prática Pedagógica Integradora, Educação Ambiental, Educação Profissional.

\section{INTEGRATION BETWEEN EDUCATION, RESEARCH AND EXTENSION: PRACTICE REPORT IN TEACHING TRAINING}

\begin{abstract}
This study is defined as a practice report developed along teaching probation which integrated the branches of teaching, research and extension, connected to our master's research in PPGEP, which aims to contribute to the integral human formation of the students of the Superior Course of Technology in Environmental Management from the critical reading and the production of short animations as environmental education tools. To aim that, we started the research on the class during the first and the second semester of 2014
\end{abstract}

in which we continued to performing interventions and extension practice. Our Theoretical base is composed by authors such as Antunes (2001), Barbosa Junior (2011), Benachio (2011), Lorenzi and Pádua (2012), Pimenta and Lima (2012), Purves (2011), Rojo (2012) and Silverstone (2005). By the end we realized that among the difficulties faced, the probation provided an opportunity of mature the integrative teaching practice and, most importantly, allowed us on sowing reflections at environmental managers in training.

KEYWORDS: Teaching Training, Integrative Pedagogical Practice, Environmental Education, Professional Education. 


\section{INTRODUÇÃO}

O Estágio de Docência é um componente curricular obrigatório que integra o Programa de Pós-graduação em Educação Profissional (PPGEP), do Instituto Federal de Educação, Ciência e Tecnologia (IFRN). Esse Programa objetiva contribuir para a elevação da qualidade social da educação profissional (IFRN, 2012). Por isso, tem como objetivo formar profissionais, em nível de pós-graduação stricto sensu para o exercício de atividades de ensino e pesquisa no campo da Educação Profissional (IFRN, 2012), fundando-se na articulação entre trabalho, ciência, tecnologia e cultura.

Por reconhecermos que o estágio é um rico instrumento de formação acadêmica, buscamos atrelar a nossa prática pedagógica à pesquisa de mestrado no PPGEP. Para tanto, integramos os eixos ensino, pesquisa e extensão. Sendo assim, nesse artigo objetivamos relatar o desenvolvimento do Estágio Docência realizado ao longo dos semestres letivos 2014.1 e 2014.2.

O estágio esteve vinculado à minha pesquisa de mestrado, configurando-se como seu elemento constituinte, por se tratar de uma pesquisa-ação. Em relação aos objetivos de ensino, buscamos, ao longo do estágio, desenvolver a criticidade dos estudantes que ingressaram em 2014.1 no curso Superior de Tecnologia em Gestão Ambiental, no IFRN, campus Natal Central, a partir do estudo sobre a repercussão do sistema de produção capitalista sobre o meio ambiente e a influência do uso das mídias como instrumento de educação ambiental.

A etapa do estágio que se refere à pesquisa teve início em 2014.1 com a observação e aplicação do questionário inicial junto à turma. E, também esteve vinculada ao período de ensino, em 2014.2, uma vez que, em meio às intervenções realizávamos também a observação participante para coleta de dados, analisando dados, (re)planejando a prática e aplicando o questionário final.

A etapa concernente à extensão, no processo de estágio, se deu em continuidade ao exercício da pesquisa, a fim de compartilhar tanto o material audiovisual produzido para trabalhar com a turma como também o que foi produzido pela turma com vistas à sensibilização da consciência ambiental de outros sujeitos. Desse modo, os gestores ambientais em potencial têm a oportunidade de exercer seu papel de educador ambiental promovendo a sensibilização de outros sujeitos quanto à preservação e/ou conservação do meio ambiente, usando como estratégia exibição de vídeos/animações.

Para consecução dos objetivos, fundamentamos nosso trabalho em autores como Antunes (2001), Barbosa Júnior (2011), Benachio (2011), Lorenzi e Pádua (2012), Pimenta e Lima (2012), Purves (2011), Rojo (2012) e Silverstone (2005). E a partir da articulação entre teoria e prática favorecida pelo estágio foi possível refletirmos sobre a docência e ressignificar a prática pedagógica.

A seguir apresentamos a reflexão acerca do estágio como espaço de integração, subdividindo-o nos itens Ensino, Pesquisa e Extensão, nos quais relatamos como foi desenvolvida nossa intervenção. E, para encerrar, trazemos algumas considerações finais. 


\section{ESTÁGIO DE DOCÊNCIA COMO ESPAÇO DE INTEGRAÇÃO}

O Estágio de Docência é uma oportunidade de maturação profissional, sobretudo no que tange à prática docente. Pois, não nascemos educadores, mas nós nos tornamos educadores em meio à prática e à reflexão sobre ela. Nesse sentido, recordamos Benachio (2011) ao defender que o professor não está pronto, pois a realidade na qual se insere é mutável, por isso, ele vai se construindo num processo dialético, elucidando o binômio teoria-prática e reflexão-ação para aprender, revisando seu saber continuamente.

Em nosso exercício cotidiano, quando temos a oportunidade de integrar ensino, pesquisa e extensão, as possibilidades de aprendizado e aperfeiçoamento do profissional em atuação se potencializam. Quando esses eixos são trabalhados de forma articulada, como tentamos fazer em nosso estágio, o diálogo entre os campos flui e a prática tem relevância intensificada.

Pimenta e Lima (2012, p. 45) nos dizem que "o estágio curricular é uma atividade teórica de conhecimento, fundamentação, diálogo e intervenção na realidade [...]". As referidas autoras defendem também a ideia, em conformidade com a intencionalidade do PPGEP, de que o estágio supervisionado para quem já exerce o magistério (nosso caso) pode se constituir como ferramenta de formação contínua ao propiciar uma reflexão sobre a própria prática e desencadear a ressignificação de saberes sobre a docência.

Foi, então, partindo dessa compreensão, que nos dispusemos a investir em nosso processo de formação pessoal e profissional por via do estágio de docência, sobretudo, durante o segundo semestre letivo de 2014 (que se materializou no período de outubro de 2014 a março de 2015).

Com base na ementa proposta para a disciplina Técnicas em Educação Ambiental, espaço do meu estágio de docência, e em articulação com os objetivos de nossa pesquisa de mestrado ${ }^{1}$, desenvolvemos as intervenções tendo como norte a interseção entre trabalho, ciência, tecnologia e cultura, com vistas à formação humana integral dos sujeitos. Essa articulação entre ensino e pesquisa se deu por reconhecermos que o espaço da sala de aula é também um laboratório de construção de conhecimentos científicos.

Embasados nessa perspectiva, nossa pesquisa-ação de mestrado utilizou o Estágio Docência como recurso estratégico para coleta dos dados e a intervenção proposta. Nesse cenário, a intervenção atrelada ao estágio de docência pautou sua sistemática na perspectiva de multiletramentos que articula a multiplicidade cultural das populações (produções culturais letradas formadas por textos híbridos de diferentes letramentos e de diferentes campos) e a multiplicidade semiótica de constituição dos textos (textos compostos por variadas linguagens) por meio dos quais se informa e se comunica (ROJO, 2012, p.13). Essas características requerem novas capacidades e práticas de compreensão e produção, que no passado eram dispensáveis, pois "as tecnologias digitais estão introduzindo novos modos de comunicação, como a criação e o uso de imagens, de sons, de animação e a combinação dessas modalidades." (LORENZI e PÁDUA, 2012, p.37).

\footnotetext{
${ }^{1}$ Nossa pesquisa de mestrado tem como objeto de estudo a educação ambiental como parte integrante da formação humana do tecnólogo em Gestão Ambiental. Desse modo, objetivamos contribuir para a formação humana integral dos discentes do Curso Superior de Tecnologia em Gestão Ambiental a partir da leitura crítica e da produção de animações de curta duração como instrumentos de educação ambiental.
} 
Um exemplo prático desses novos modos de comunicação que combinam escrita, imagens e sons pode ser representado pelas animações construídas a partir da técnica do stop-motion. Um produto que requer do seu espectador novos ou múltiplos letramentos.

Com os hipertextos e hipermídias fazem-se necessárias novas ferramentas e novas práticas tanto de produção quanto de análise crítica do que foi produzido e circula na sociedade, práticas que favoreçam a percepção acerca do cruzamento de interesses mercantis, estéticos e comunicacionais dos textos publicitários, por exemplo. Foi essa compreensão que utilizamos no estágio, sobretudo, nos momentos de discussão sobre os gêneros explorados em sala, instigando a reflexão críticas dos sujeitos.

E por entender que a mídia (seus recursos) é um dos alvos de análise feita pelos multiletramentos a colocamos como cerne de nossas reflexões no universo da educação ambiental, principalmente, quando lembramos que:

É no mundo mundano que a mídia opera de maneira mais significativa. Ela filtra e molda realidades cotidianas, por meio de suas representações singulares e múltiplas, fornecendo critérios, referências para a condução da vida diária, para a produção e a manutenção do senso comum. (SILVERSTONE, 2005, p.20)

Com base na defesa de Silverstone (2005), consideramos que a mídia é capaz de influenciar o aumento do consumo de supérfluos, por exemplo, que gera sérias consequências para o meio ambiente, devido ao acúmulo de resíduos que é gerado pelo consumismo.

Então, buscando desenvolver um trabalho de multiletramentos com alunos adultos, pensamos em transformar a sala de aula em uma "academia de ginástica", onde se exercita o cérebro a receber estímulos e desenvolver inteligência, conforme nos diz Antunes (2001).

Assim, compreendendo a preeminência de momentos vivenciais, planejamos nossa intervenção fazendo uso de variados recursos para suscitar a criticidade dos alunos na direção da (re)significação de suas práticas cotidianas em relação ao meio ambiente.

Para tanto, escolhemos trabalhar com diferentes gêneros textuais, imagéticos e audiovisuais, e para a culminância do estágio, trabalhar com a animação a partir do stop-motion. Entendemos que essa escolha (trabalho com a animação) atende à perspectiva dos multiletramentos. Para justificá-la, recorremos a Barbosa Júnior (2011) quando nos diz que a animação é uma arte multimídia, pois combina diversas técnicas de produção.

Tomando essas reflexões como base, planejamos as atividades de ensino e extensão apresentadas a seguir.

\subsection{Ensino}

As atividades de ensino foram desenvolvidas sob a supervisão da Prof.a Maria Agripina Pereira Rebouças, junto à turma do curso de Tecnologia em Gestão Ambiental que ingressou no semestre 2014.1, especificamente, na disciplina Técnicas de Educação Ambiental com uma carga horária de 40 horas-aula (h/a). Dessa carga horária, o estágio compreendeu 26h/a, distribuídas em 11 encontros com a turma (nove encontros de $2 \mathrm{~h} / \mathrm{a}$ e dois encontros de $4 \mathrm{~h} / \mathrm{a}$ ), mais $10 \mathrm{~h}$ referentes ao planejamento considerando a seleção de material, a produção de audiovisuais (stop-motion), as leituras prévias e a construção dos slides. 
No decorrer do semestre 2014.2, em meio às aulas, a participação e desempenho dos estudantes da turma, alguns ajustes no planejamento prévio foram necessários, bem como mudanças de estratégias empregadas, a fim de atender aos objetivos propostos. Como exemplo, podemos citar o encaminhamento planejado de leituras para serem realizadas em casa, que se mostrou inviável, tendo em vista a rotina enfrentada pela maioria da turma. Desse modo, os estudantes chegavam às aulas sem terem realizado o trabalho encaminhado. Ao perceber isso, passamos a realizar os momentos de prática na própria sala de aula, bem como a leitura e discussão de textos.

Para assegurar o envolvimento e a reflexão dos estudantes, fizemos uso de aulas expositivas dialogadas, questões problematizadoras, estudos de alguns textos teóricos, exibição de vídeos (filmes, animações e documentários), dinâmicas de sensibilização, exploração de alguns gêneros textuais (como notícia, panfleto, cordel, letra de música e outros), planejamento de situações educativas (por parte da turma), confecção de panfletos de educação ambiental, produção de vídeos, momentos de socialização das produções e momento de avaliação.

Mediante o contato com a turma, íamos nos aproximado e conhecendo um pouco mais as características de cada um. Desse modo, algumas posturas ou comentários de estudantes tornavam-se alvo de aulas seguintes, quanto à escolha da temática ou à seleção das imagens e/ou textos, ou das questões problematizadoras para reflexão. Quesitos como integração, espírito de equipe, criticidade e perfil educador foram objetos de reflexão e prática durante os encontros.

Para trabalhar o perfil educador, desafiamos a turma a planejar atividades educativas, partindo de textos de sensibilização, como letras de músicas, cordéis, poemas ou contos.

Outra atividade executada foi a análise de propagandas de revistas, na qual os gestores ambientais em formação precisaram refletir como educadores ambientais, questionando-se sobre a utilidade dos produtos anunciados e os impactos sobre o meio ambiente, além da estreita relação entre a propaganda do produto, o consumismo e o capitalismo. Essa atividade foi seguida do planejamento e confecção de um panfleto sobre a Área de Preservação Ambiental de Jenipabu $(\mathrm{APAJ})^{2}$, tendo como alvo a conscientização ambiental dos sujeitos que vivem ou frequentam o lugar. Desse modo, a atividade oportuniza a leitura crítica e a produção de um gênero textual com fim educativo, pois a mídia também pode ter aspectos positivos no que tange ao meio ambiente.

A atividade de produção de vídeo com a técnica do stop-motion foi a culminância da nossa intervenção. Após o trabalho realizado de leitura crítica e produção de alguns textos de cunho midiático, encaminhamos a atividade de produção de um vídeo/animação de curta duração, com base na experiência vivenciada pelo Projeto Integrador ${ }^{3}$, com o objetivo de sensibilizar os espectadores em relação à consciência ambiental. Assim, mais uma vez, a turma precisou mobilizar sua criatividade, suas habilidades e os conhecimentos construídos pelas experiências vivenciadas.

O trabalho com o stop-motion também estreitou os laços da turma, pois requereu um trabalho em equipe. $\mathrm{O}$ depoimento dos vários alunos no encontro final da disciplina confirmou

\footnotetext{
${ }^{2}$ APA criada pelo Decreto Estadual no 12.620 de 17 de maio de 1995 com objetivo de proteger e preservar os ecossistemas dessa região que tem intensa atividade turística. Mais informações disponíveis no site do IDEMA http://www.idema.rn.gov.br/.

${ }^{3}$ Os Projetos Integradores objetivam fortalecer a articulação da teoria com a prática, valorizando a pesquisa individual e coletiva, a fim de promover oportunidades de reflexão ao futuro tecnólogo sobre a tomada de decisões mais adequadas a sua atuação social e profissional (IFRN, 2012).
} 
uma maior integração da turma após esse trabalho, além de o avaliarem como proveitoso trabalho e com rico potencial para sensibilização da consciência ambiental de outros sujeitos e revisão da prática cotidiana dos próprios graduandos em gestão ambiental.

O stop-motion construído pela turma fala sobre a importância da preservação do bioma caatinga e apresenta as consequências da ação antrópica sobre esse bioma para a vida no planeta. O vídeo é curto, mas apresenta uma mensagem educadora.

Durante as aulas desenvolvidas, para sensibilizar os estudantes, utilizamos como recursos didáticos: projetor multimídia; notebook (com editor simples de vídeo); caixinhas de som para notebook; animações de curta duração; filmes; documentários; tangran; textos diversos, entre outros recursos.

De acordo com a participação dos estudantes nos encontros com a turma, seu desempenho era avaliado de forma contínua, com predomínio dos aspectos qualitativos. Essa avaliação servia de base para repensar o planejamento prévio do estágio de docência e rever as atividades dos encontros seguintes. Para a sistematização e atribuição das notas, foram consideradas tanto a participação nas discussões quanto a realização das atividades propostas encaminhadas.

\subsection{Pesquisa}

A etapa da pesquisa, diferentemente dos demais momentos deste estágio, iniciou ainda no semestre letivo 2014.1, semestre de ingresso dessa turma no curso de Tecnologia em Gestão Ambiental.

A pesquisa teve início antes mesmo de nossa matrícula no Estágio de Docência, pois identificamos que, no primeiro período do curso, era ofertada à turma a disciplina Cidadania, Ética e Meio Ambiente (CEMA). Essa disciplina seria a iniciação da turma em relação aos conhecimentos específicos referentes ao campo da Gestão Ambiental. Um momento importante para nos aproximarmos da turma, identificarmos suas concepções prévias, observarmos suas posturas quanto ao meio ambiente, sua participação nas discussões e o nível de criticidade trazido da sua formação anterior. Outro fator considerado para escolha dessa disciplina foi o fato de ser prérequisito para a disciplina Técnicas de Educação Ambiental, na qual faríamos o estágio de ensino, para realizar as intervenções da pesquisa-ação.

Iniciamos, então, a pesquisa empírica junto à turma no dia 13 de agosto de 2014, frequentando as aulas de CEMA, com 02 encontros semanais de $2 \mathrm{~h} / \mathrm{a}$ cada, realizando a observação em 10 encontros, entre os meses de agosto e setembro.

No primeiro contato com a turma, apresentamos a proposta da pesquisa de mestrado, justificando a minha presença a partir daquele momento nas aulas da disciplina CEMA. A partir do segundo encontro, apresentamos o Termo Livre Esclarecido de Consentimento e entregamos o questionário inicial aos alunos que se dispunham a participar da pesquisa (apenas 16 de 30 matriculados). Esse questionário objetivava identificar as concepções dos sujeitos acerca do meio ambiente e sua percepção sobre as influências do modo de produção capitalista sobre o meio.

Nas aulas que acompanhamos, em decorrência da formação inicial do professor titular em Direito, as discussões gestadas na disciplina, se referiam principalmente à construção, aplicação e atualização das leis ambientais, órgãos consultivos, deliberativos ou fiscalizadores do meio ambiente, além de formas de denúncia e participação/ intervenção social. Os alunos geralmente 
apresentavam relatos ou questionamentos acerca de experiências vivenciadas no seu campo de trabalho ou situações que presenciaram, ouviram falar ou leram a respeito. Essa participação era escassa e geralmente eram os mesmos que se pronunciavam.

Quanto às posturas adotadas pela turma, demonstraram ter educação ambiental e não aparentaram ser consumistas em excesso. Observamos poucas atitudes de desrespeito ao meio ambiente: embalagem de biscoito no chão, que permaneceu no chão durante toda a aula, assim como bolinhas de papel nos trilhos da janela; alunos com celulares de modelos atuais e alguns com 03 aparelhos diferentes; aluno comentou que tem em casa, congeladas para consumo, várias arribaçãs (ave em risco de extinção). Percebemos também escasso poder de argumentação, criticidade e envolvimento com questões ambientais, a partir das falas feitas pelos alunos no decorrer dessas aulas. Os dados apresentados pelas respostas dos questionários reforçam essa compreensão.

Pensando nesse cenário, planejamos as intervenções para despertar e/ou desenvolver a criticidade da turma quanto à vinculação do capitalismo ao consumismo e sua repercussão sobre o meio ambiente, a ser trabalhada no decorrer do estágio de docência.

Então, demos início à segunda etapa da pesquisa junto à turma, em meio ao período do estágio destinado ao ensino. Esse período também se configurou como pesquisa visto que nosso trabalho de mestrado tem como metodologia a pesquisa-ação, que faz a coleta de dados, mas também programa e executa intervenções junto ao universo pesquisado com vista a melhoria da realidade local. Por isso, em concomitância ao ensino, desenvolvíamos a pesquisa exercendo as intervenções, mediando saberes, promovendo discussões, aguçando a criticidade dos sujeitos, estimulando sua reflexão, mobilizando conhecimentos, habilidades e criatividade e colocando-os em prática, a fim de contribuirmos com a formação humana integral desses gestores em formação e, por exigência da profissão, também educadores.

Associando as falas dos alunos na dinâmica de apresentação às posturas observadas no semestre anterior percebemos que os alunos que participavam com mais frequência das discussões eram aqueles que já tinham uma outra formação como técnicos ou graduados, sobretudo, quando se tratavam de áreas afins: licenciados em História, em Ciências Biológicas, em Ecologia e em Ciências Contábeis; técnicos em Petróleo e Gás, em Segurança do Trabalho e em Estradas. Alguns também já atuam na área ambiental.

Para planejar nossas intervenções, consideramos alguns dados obtidos a partir do questionário inicial: $44 \%$ consideram que o meio ambiente se limita à natureza; $18 \%$ consideram que o meio ambiente é algo externo ao indivíduo; $12 \%$ consideram que a tecnologia nada ou pouco interfere sobre o meio ambiente; $44 \%$ discordam que o consumismo repercuta sobre a poluição. Elementos como esses foram alvo do nosso trabalho visando ampliarmos as concepções dos sujeitos da pesquisa para perceberem o quanto os fatores históricos, sociais e econômicos afetam o meio ambiente. Então, durante as aulas, mediávamos conhecimentos a partir dos questionamentos e problematizações apresentados, para aguçar a criticidade dos sujeitos e fazêlos pensar e repensar sua postura cotidiana, bem como envolvê-los em prática de educação ambiental, tendo em vista que essa é uma exigência de sua formação como gestores ambientais, segundo o projeto do curso. Portanto, a todo momento, relembrávamos à turma que, enquanto gestores ambientais em potencial, deveriam ser, antes de tudo, educadores ambientais. 
Após o encerramento do estágio, para finalizar a coleta de dados, enviamos por e-mail o Questionário Final que avalia a intervenção realizada e verifica se houve avanços nas concepções dos estudantes quanto à relação entre o homem e o meio ambiente.

\subsection{Extensão}

A proposta de extensão definida em nosso plano de atuação se referia à participação na disciplina Seminário de Orientação do Projeto Integrador, indo a campo, no período de 05 a 07 de fevereiro de 2015, visitar o município de Carnaúba dos Dantas onde os alunos iriam coletar dados, analisa-los e propor intervenções para a melhoria da qualidade de vida local.

A disciplina responsável pelo Projeto Integrador realizado no segundo período do curso superior de Tecnologia em Gestão Ambiental envolve as disciplinas Geologia, Ecologia, Técnicas de Educação Ambiental e Cartografia Ambiental cujos professores titulares são os orientadores dos grupos para a intervenção no município a ser visitado.

Escolhido o município, foram eleitos como temas de pesquisa sobre o lugar: agricultura familiar, pinturas rupestres, cerâmicas e Monte do Galo. Após isso, turma foi subdividida em 04 grupos e cada grupo recebeu um tema e um orientador.

Realizadas as pesquisas prévias sobre o município a ser visitado, principalmente no que tange aos temas definidos, a turma junto com seus professores organizou estratégias de intervenção e coletas de dados: roda de conversa com a comunidade local, na qual os moradores relataram suas experiências e estratégias de sobrevivência; o teatro de fantoches, no qual os alunos promoveram junto à comunidade uma reflexão sobre o desmatamento.

Para conhecer melhor o município, a turma visitou um sítio onde estão preservadas algumas pinturas rupestres, assim como olarias e o Monte do Galo. Nesses ambientes, se depararam com os impactos causados pelo ser humano na degradação do ambiente, bem como do patrimônio paisagístico, histórico e cultural.

De acordo com os relatos de alguns estudantes da turma em questão, após a estadia em Carnaúba dos Dantas, as experiências ali vivenciadas, as informações colhidas e o conhecimento construído, eles regressaram à Natal/RN reflexivos, mais integrados e atentos à sua responsabilidade como futuros gestores ambientais. Esse era um dos desafios para os alunos ao fazer o Relatório do Projeto Integrador, não apenas relatar as descobertas, estudos e aprendizados, mas propor estratégias de intervenção para melhorar a qualidade de vida e do meio ambiente local.

Concluídos os relatórios, os grupos participaram de um seminário, no qual cada grupo apresentou seu trabalho a uma banca formada por dois professores do IFRN, Campus Natal Central.

O seminário, coordenado por uma das professoras titulares das disciplinas que compõem o Projeto Integrador realizado com a turma em questão, ocorreu nos dias 23 e 24 de março de 2015, no Auditório do Museu de Minérios do IFRN, Campus Natal Central, das 19h às 22h.

No primeiro dia, a turma realizou o teatro de fantoches que havia sido apresentado no município visitado. Na sequência, dois professores do IFRN, convidados, apresentaram os resultados das pesquisas que realizaram sobre Carnaúba dos Dantas, seu município de origem. 
No segundo dia do seminário, a turma apresentou o vídeo Caatinga construído a partir da técnica do stop-motion trabalhado na disciplina Técnicas de Educação Ambiental em meio ao estágio docência mencionado neste relatório. Na ocasião, foi-nos dada a oportunidade de explicar a proposta de trabalho desenvolvida com a turma, referente a nossa pesquisa de mestrado. Em seguida, os grupos apresentaram seus relatórios do Projeto Integrador às bancas, que fizeram as arguições, encerrando com a palavra de fechamento de seus orientadores.

O Projeto Integrador se configurou como um importante momento no processo de formação integral dos sujeitos, sensibilizando-os para a intervenção social, não se limitando a uma formação para o mercado de trabalho ou a continuidade na formação acadêmica, mas imprimindo significado e relevância ao seu estudo e formação profissional.

Embora, tenhamos acompanhado poucos momentos da turma em meio ao desenvolvimento desse Projeto Integrador, não foi possível participar dele em sua integralidade.

Para que a extensão não deixasse de ocorrer no que tange a nossa pesquisa, criamos um canal no You Tube para a divulgação dos vídeos produzidos para e pela turma com a técnica de stop-motion. O objetivo do canal é promover a reflexão a partir da exibição dos vídeos de sensibilização para consciência ambiental dos espectadores. O canal está em sua fase inicial de alimentação, contendo apenas os vídeos apresentados à turma durante o estágio e o vídeo produzido pela turma. Esse material está disponível no canal https://www.youtube.com/chan nel/UCsw53uHuNDgJZ9KRaaDhZ5w para acesso de qualquer pessoa, tanto para visualização como para utilização ou compartilhamento. Nesse processo de criação, alimentação, manutenção e divulgação do canal, computamos $4 \mathrm{~h}$ de atividade, tendo em vista que os vídeos estavam previamente prontos.

Desse modo, com a produção e o compartilhamento dos vídeos na internet colocamos em prática a ideia dos multiletramentos, uma vez que reunimos diferentes elementos (imagens, texto escrito e músicas) para a composição do gênero audiovisual e o disponibilizamos na rede para que outros tenham acesso e dele façam uso.

\section{CONSIDERAÇÕES FINAIS}

O estágio de docência é um momento de aprendizado, no qual repensamos nosso papel docente, compartilhando aprendizados e aprendendo a mobilizar conhecimentos para mediar novos aprendizados junto ao grupo com o qual se trabalha. É um momento de formação e maturação profissional. Um momento de investigação, de aprofundar conhecimentos, de pesquisar e colocar em prática o conhecimento construído até então.

É notório que a distribuição da carga horária do estágio em ensino, pesquisa e extensão propicia ao estagiário oportunidades variadas de aprendizado. Intervindo, compartilhando e pensando sobre a pesquisa científica, suas etapas, objetivos e delineamentos. Não foram apenas períodos de coleta de dados, mas, sobretudo, oportunidade de reflexão sobre a docência e ressignificação da prática pedagógica.

Esse estágio, um caso específico tendo em vista que nosso trabalho de mestrado utiliza como metodologia a pesquisa-ação, se configurou como excelente oportunidade para me aproximar dos sujeitos da pesquisa, conhecê-los um pouco mais e rever as hipóteses elencadas no início do processo de trabalho. Sendo assim, consideramos que foi um desafio enfrentado que 
trouxe fortes marcas em nossas constatações, redirecionando os encaminhamentos de nossa pesquisa.

\section{REFERÊNCIAS}

1. ANTUNES, Celso. Como transformar informações em conhecimento. 4 ed. Petrópolis, Rio de Janeiro: Editora Vozes, 2001. Fascículo 2.

2. BARBOSA JÚNIOR, Alberto Lucena. A arte da animação: teoria e estética através da história. 3 ed. São Paulo: Editora SENAC São Paulo, 2011, 426p.

3. BENACHIO, Marly das Neves. Como os professores aprendem a ressignificar sua docência? São Paulo: Editora Paulinas, 2011 (Coleção educação em foco).

4. IFRN, Instituto Federal de Educação, Ciência e Tecnologia do Rio Grande do Norte. Regimento do Programa de Pós-graduação em Educação Profissional. Natal/RN: IFRN, 2012. Disponível em:<http://portal.ifrn.edu.br/ensino/cursos/cursos-de-pos-graduacao/stricto-

sensu/ppgep/documentos/legislacao/regimento-mestrado-versao-conselhos-finalizado>.

Acesso em: 10 set 2014.

5. IFRN, Instituto Federal de Educação, Ciência e Tecnologia do Rio Grande do Norte. Projeto Político-Pedagógico do IFRN: uma construção coletiva. Natal/RN: IFRN, 2012. Disponível em: <http://portal.ifrn.edu.br/institucional/arquivos/documento-base-do-ppp>. Acesso em: 10 set 2014.

6. IFRN, Instituto Federal de Educação, Ciência e Tecnologia do Rio Grande do Norte. Projeto Político-Pedagógico do Curso Superior de Tecnologia em Gestão Ambiental na modalidade presencial. Natal/RN: $\quad 2012 . \quad$ IFRN, Disponível em: <http://portal.ifrn.edu.br/campus/natalcentral/cursos/cursos-de-graduacao/gestaoambiental.html>. Acesso em: 10 set 2014.

7. LORENZI, Gislaine Cristina Correr; PÁDUA, Tainá-Rekã Wanderley de. Blog nos anos iniciais do fundamental. In: ROJO, Roxane; MOURA, Eduardo. (Orgs). Multiletramentos na escola. Parábola Editorial, 2012, Cap. 2

8. PIMENTA, Selma Garrido; LIMA, Maria Socorro Lucena. Estágio e Docência. 7. ed. São Paulo: Cortez, 2012.

9. PURVES, Barry. Stop-motion. Porto Alegre: Bookman, 2011. 200p. (Animação Básica 2).

10. ROJO, Roxane; MOURA, Eduardo (Org.). Multiletramentos na escola. São Paulo: Parábola Editorial, 2012. 264p.

11. SILVERSTONE, Roger. Por que estudar a mídia? 2 ed. Edições Loyola. São Paulo, 2005. Tradução: Milton Camargo Mota. 